\title{
Umbilical cord blood troponin I, myoglobin and CK-MB in neonatal hypoxic ischemic encephalopathy and the clinical significance
}

\author{
BIN WAN ${ }^{1}$, XUEXIA PAN $^{2}$, JINSHUAI MA ${ }^{1}$, YAO LUO ${ }^{1}$, JUNYAN LIU ${ }^{1}$ and GUOYING ZHAO ${ }^{1}$ \\ ${ }^{1}$ NICU, Binzhou Medical University Hospital, Binzhou, Shandong 256000; \\ ${ }^{2}$ Department of Pediatric, Binzhou People's Hospital, Binzhou, Shandong 256610, P.R. China
}

Received September 6, 2019; Accepted November 4, 2019

DOI: $10.3892 /$ etm.2019.8248

\begin{abstract}
Associations of serum S-100 $\beta$, cystatin C (Cys-C) and C-reactive protein (CRP) with umbilical cord blood troponin I (TnI), myoglobin $(\mathrm{Mb})$ and creatine kinase-MB (CK-MB) in neonatal hypoxic ischemic encephalopathy (NHIE) and the clinical significance were explored. A total of 40 patients with NHIE treated in the Binzhou Medical University Hospital were selected as observation group, while another 40 healthy neonates in the same period were selected as control group. The related data of all subjects were collected, and the levels of serum $S-100 \beta$ protein, CRP and Cys-C, and umbilical cord blood TnI, Mb and CK-MB were compared between the two groups. Associations of the neonatal behavioral neurological assessment (NBNA) score with the changes in serum S-100 $\beta$ protein, CRP and Cys-C and umbilical cord blood TnI, Mb and CK-MB were analyzed. The univariate and multivariate logistic regression analyses were performed to determine the risk factors for NHIE. In observation group, the levels of serum $\mathrm{S}-100 \beta$ protein, CRP and $\mathrm{Cys}-\mathrm{C}$ were significantly higher than those in control group, and the levels of umbilical cord blood TnI, Mb and CK-MB were also significantly higher than those in control group. The NBNA score was negatively correlated with the changes in serum $\mathrm{S}-100 \beta$ protein, CRP and Cys-C as well as the umbilical cord blood TnI, Mb and CK-MB. The levels of serum S-100 $\beta$ protein, CRP and Cys-C, and umbilical cord blood TnI, Mb and CK-MB were related risk factors for NHIE. The increased levels of serum S-100 $\beta$ protein, CRP and Cys-C, and umbilical cord blood TnI, Mb and CK-MB were independent risk factors for NHIE. In NHIE patients, the levels of serum $\mathrm{S}-100 \beta$ protein, CRP and Cys-C, and umbilical
\end{abstract}

Correspondence to: Dr Guoying Zhao, NICU, Binzhou Medical University Hospital, 661 Huanghe 2nd Road, Bincheng, Binzhou, Shandong 256000, P.R. China

E-mail:kkaqz457@163.com

Key words: neonatal hypoxic ischemic encephalopathy, serum S-100 $\beta$, cystatin C, CRP, umbilical cord serum, troponin I, myoglobin, $\mathrm{CK}-\mathrm{MB}$ cord blood TnI, Mb and CK-MB all significantly increased, and they have negative correlation with the nervous system function after onset.

\section{Introduction}

Neonatal hypoxic ischemic encephalopathy (NHIE) can be caused by various perinatal factors, which mainly leads to neonatal ischemia and hypoxia in the central nervous system, and decline or even suspension of cerebral blood flow, as well as secondary fetal or neonatal hypoxic injury in the central nervous system (1). NHIE is the most common complication of neonatal asphyxia, and also the major cause of mental retardation in children. Studies have shown that $30 \%$ of NHIE patients suffer from disorders of mental development (2). The moderate-severe NHIE patients, although survived, have severe neurological sequelae, such as cerebral palsy, epilepsy and dysgnosia, causing serious psychological and economic burden on the families of the child patient and society (3).

Asphyxia is considered as the most direct cause of NHIE (4), during which central nervous system lesions are caused by the decline in the neonatal blood oxygen saturation mostly due to fetal-maternal circulation and gas exchange disorders (5). A study proved (6) that NHIE may be complicated with multiple organ dysfunctions after onset, and the organ dysfunction becomes more severe with the increasing severity of asphyxia, exerting a more serious negative impact on the long-term prognosis, and even affecting the quality of life of the child patients. Therefore, early detection, diagnosis and treatment of NHIE are of important significance for reducing the morbidity and mortality rates of the disease, which is also an important method to improve the neonatal birth quality in China. The present study explored the associations of serum S-100 $\beta$, cystatin C (Cys-C) and C-reactive protein (CRP) with umbilical cord blood troponin I (TnI), myoglobin (Mb) and creatine kinase-MB (CK-MB) in NHIE patients.

\section{Patients and methods}

General data. A total of 40 patients with NHIE treated in the Binzhou Medical University Hospital (Binzhou, China) from March 2017 to June 2019 were selected as observation 
group, while another 40 healthy neonates in the same period were selected as control group. All child patients met the diagnostic criteria for NHIE of the Society of Pediatrics, Chinese Medical Association in 2015, and they had high-risk factors for perinatal asphyxia. According to the neonatal birth mode, gestational weeks, Apgar scores immediately after birth and at 1 and 5 min after birth, the history of birth asphyxia, and diagnosis of neurological symptoms, the following subjects were excluded: Mothers complicated with severe systemic infection during pregnancy or taking immunosuppressive drugs and/or glucocorticoids during pregnancy, neonates definitely with congenital genetic diseases and/or deformity after birth, mothers complicated with severe respiratory system, digestive system or urinary system infection, or premature rupture of membranes for more than $24 \mathrm{~h}$ during enrollment, or mothers who used analgesic sedative drugs in the perinatal period or definitely had hemorrhagic shock. In observation group, there were 26 males and 14 females, the gestational age at birth was $32-42$ weeks with an average of $37.6 \pm 0.4$ weeks, and the birth weight was 2,000-4,500 $\mathrm{g}$ with an average of 3,200.0 $\pm 100.0 \mathrm{~g}$. In control group, there were 25 males and 15 females, the gestational age at birth was 32-42 weeks with an average of $37.7 \pm 0.5$ weeks, and the birth weight was $2,000-4,500 \mathrm{~g}$ with an average of $3,200.5 \pm 100.5 \mathrm{~g}$. The sex, gestational age at birth and birth weight had no statistically significant differences between the two groups ( $\mathrm{P}>0.05)$. This study was approved by the Ethics Committee of the Hospital Attached to the Binzhou Medical University. Signed informed consents were obtained from all the parents of the child participants before the study.

Methods. The related data of all subjects were collected, and the levels of serum S-100 $\beta$ protein, CRP and Cys-C, and umbilical cord blood TnI, Mb and CK-MB were compared between the two groups. Moreover, the associations of the neonatal behavioral neurological assessment (NBNA) score with the changes in serum S-100 $\beta$ protein, CRP and Cys-C and umbilical cord blood TnI, Mb and CK-MB were analyzed. The univariate and multivariate logistic regression analyses were performed to determine the risk factors for NHIE.

Evaluation criteria. The specimens of serum S-100 $\beta$ protein [enzyme-linked immunosorbent assay (ELISA) (R\&D Systems), <0.5 $\mu \mathrm{g} / \mathrm{l}]$, CRP (ELISA, $<10 \mathrm{mg} / \mathrm{l}$ ) and Cys-C (ELISA, 0.51-1.09 $\mathrm{mg} / \mathrm{l})$ were obtained from the venous blood of neonates. The specimens of TnI (ELISA, 0-0.034 ng/ml), Mb (ELISA, 0-121 ng/ml) and CK-MB (ELISA, 109-245 ng/ml) were obtained from the umbilical cord blood via puncture after the umbilical cord was cut at 1-2 min postnatally, and they were sent for detection within $15 \mathrm{~min}$. The neurobehavioral ability of neonates was examined using the NBNA under a quiet, warm and semi-dark environment, and the neonates were breast-fed and helped to sleep at $1 \mathrm{~h}$ before assessment. The NBNA score includes the behavioral ability (6 major items), passive muscle tension (4 major items), active muscle tension (4 major items) and primary reflex ( 3 major items). The score of $\geq 37$ points indicates normal ability, score of $35-36$ points indicates the suspected brain injury, and score of $<35$ points indicates brain injury. The lower the score is, the more severe the brain injury will be.
Table I. Comparison of levels of serum S-100 $\beta$ protein, CRP and Cys-C between the two groups (mean $\pm \mathrm{SD}$ ).

\begin{tabular}{lccc}
\hline & $\begin{array}{c}\mathrm{S}-100 \beta \\
(\mu \mathrm{g} / \mathrm{l})\end{array}$ & $\begin{array}{c}\mathrm{CRP} \\
(\mathrm{mg} / \mathrm{l})\end{array}$ & $\begin{array}{c}\text { Cys-C } \\
(\mathrm{mg} / \mathrm{l})\end{array}$ \\
\hline Observation group & $1.3 \pm 0.2$ & $24.4 \pm 1.6$ & $2.1 \pm 0.1$ \\
Control group & $0.4 \pm 0.1$ & $7.4 \pm 0.3$ & $0.8 \pm 0.1$ \\
t-value & 25.456 & 66.047 & 58.138 \\
P-value & $<0.001$ & $<0.001$ & $<0.001$ \\
\hline
\end{tabular}

CRP, C-reactive protein; Cys-C, cystatin C.

Table II. Comparison of levels of umbilical cord blood TnI, $\mathrm{Mb}$ and $\mathrm{CK}-\mathrm{MB}$ between the two groups ( $\mathrm{ng} / \mathrm{ml}$, mean $\pm \mathrm{SD}$ ).

\begin{tabular}{lccc}
\hline & TnI & Mb & CK-MB \\
\hline Observation group & $0.057 \pm 0.002$ & $145.3 \pm 3.5$ & $287.5 \pm 15.3$ \\
Control group & $0.023 \pm 0.001$ & $102.3 \pm 1.8$ & $189.2 \pm 9.8$ \\
t-value & 96.167 & 69.099 & 34.217 \\
P-value & $<0.001$ & $<0.001$ & $<0.001$
\end{tabular}

TnI, troponin I; Mb, myoglobin; CK-MB, creatine kinase-MB.

Statistical analysis. Statistical Product and Service Solutions (SPSS) 20.0 software (IBM Corp.) was used for statistical processing. Measurement data were expressed as mean \pm standard deviation (mean $\pm \mathrm{SD}$ ). t t-test was performed for the comparison of means between two groups, and $\chi^{2}$ test for the comparison of rates between two groups. $\mathrm{P}<0.05$ indicates statistically significant difference.

\section{Results}

Comparison of the levels of serum $S-100 \beta$ protein, CRP and $C y s-C$ between the two groups. In observation group, the levels of serum S-100 $\beta$ protein, CRP and Cys-C were significantly higher than those in control group $(\mathrm{P}<0.05)$ (Table I).

Comparison of the levels of umbilical cord blood TnI, Mb and $C K-M B$ between the two groups. In observation group, the levels of umbilical cord blood TnI, Mb and CK-MB were also obviously higher than those in control group $(\mathrm{P}<0.05)$ (Table II).

Correlation analysis between NBNA score and changes in serum $S-100 \beta$ protein, $C R P$ and $C y s-C$. The NBNA score was negatively correlated with the changes in serum $S-100 \beta$ protein, CRP and Cys-C $(\mathrm{P}<0.05)$ (Table III and Figs. 1-3).

Correlation analysis between NBNA score and changes in umbilical cord blood TnI, Mb and CK-MB. The NBNA score was also negatively correlated with the changes in umbilical cord blood TnI, Mb and CK-MB $(\mathrm{P}<0.05)$ (Table IV and Figs. 4-6). 
Table III. Correlation analysis between NBNA score and changes in serum S-100 $\beta$ protein, CRP and Cys-C.

\begin{tabular}{lll}
\hline & r-value & P-value \\
\hline Serum S-100 $\beta$ protein level & -0.8535 & $<0.001$ \\
Serum CRP level & -0.7371 & $<0.001$ \\
Serum Cys-C level & -0.8115 & $<0.001$ \\
\hline
\end{tabular}

NBNA, neonatal behavioral neurological assessment; CRP, C-reactive protein; Cys-C, cystatin C.

Table IV. Correlation analysis between NBNA score and changes in umbilical cord blood TnI, Mb and CK-MB.

\begin{tabular}{lcc}
\hline & r-value & P-value \\
\hline Umbilical cord blood TnI level & -0.6716 & $<0.001$ \\
Umbilical cord blood Mb level & -0.7967 & $<0.001$ \\
Umbilical cord blood CK-MB level & -0.9140 & $<0.001$ \\
\hline
\end{tabular}

NBNA, neonatal behavioral neurological assessment; TnI, troponin I; $\mathrm{Mb}$, myoglobin; CK-MB, creatine kinase-MB.

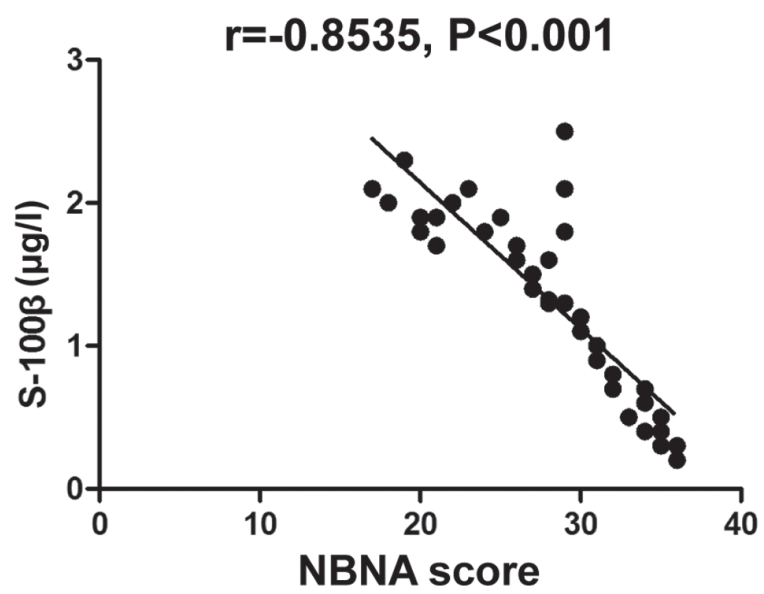

Figure 1. Correlation analysis between NBNA score and serum S-100 $\beta$ protein level. NBNA, neonatal behavioral neurological assessment.

Univariate analysis for risk factors for NHIE. According to the univariate analysis, the levels of serum S-100 $\beta$ protein, $\mathrm{CRP}$ and Cys-C, and umbilical cord blood TnI, Mb and CK-MB were related risk factors for NHIE (Table V).

Multivariate logistic regression analysis for risk factors for NHIE. According to the multivariate logistic regression analysis, the increased levels of serum $\mathrm{S}-100 \beta$ protein, CRP and Cys-C, and umbilical cord blood TnI, Mb and CK-MB were independent risk factors for NHIE (Table VI).

\section{Discussion}

The most important cause of NHIE is neonatal perinatal asphyxia, which results in neonatal hypoxic-ischemic injury $r=-0.7371, P<0.001$

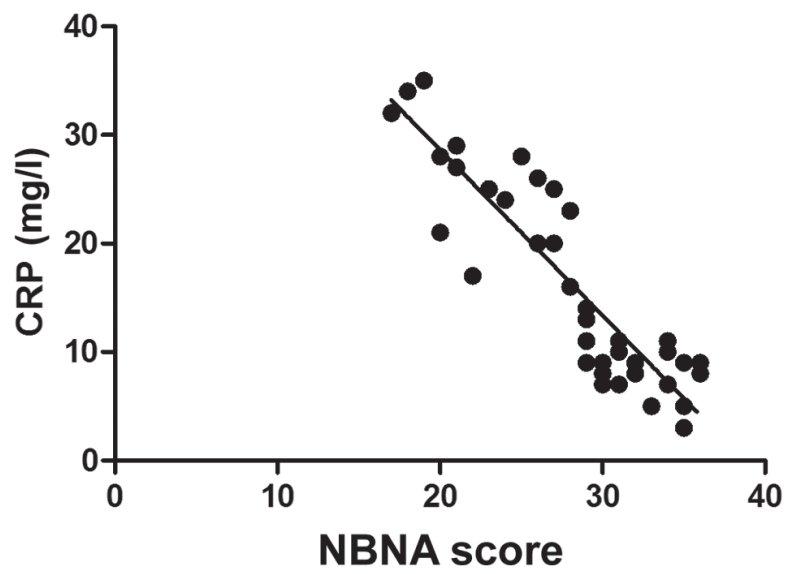

Figure 2. Correlation analysis between NBNA score and serum CRP level. NBNA, neonatal behavioral neurological assessment; CRP, C-reactive protein.

$$
r=-0.8115, P<0.001
$$

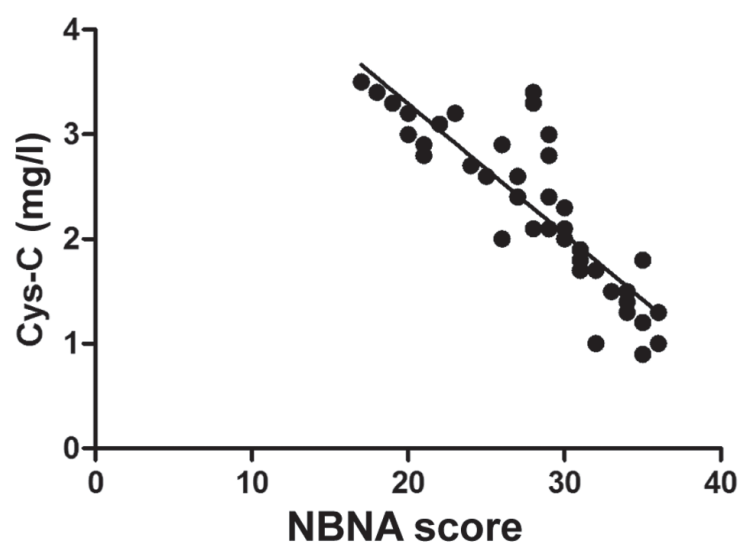

Figure 3. Correlation analysis between NBNA score and serum Cys-C level. NBNA, neonatal behavioral neurological assessment; Cys-C, cystatin C.

$$
r=-0.6716, P<0.001
$$

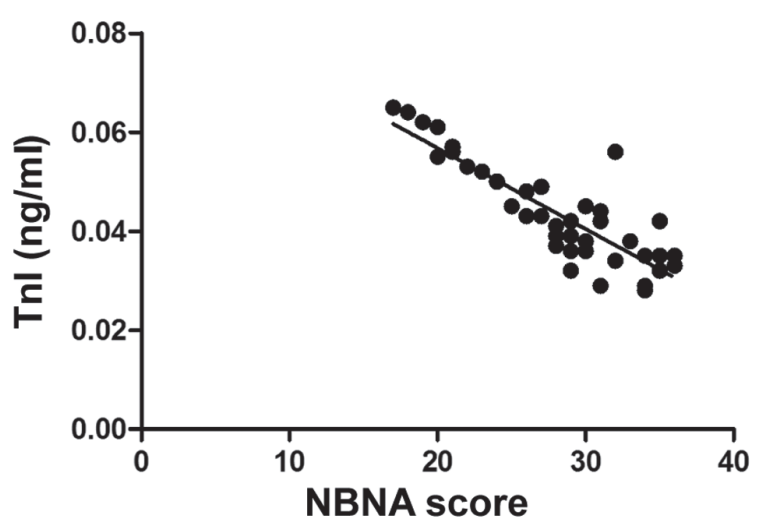

Figure 4. Correlation analysis between NBNA score and umbilical cord blood TnI level. NBNA, neonatal behavioral neurological assessment. NBNA, neonatal behavioral neurological assessment; TnI, troponin I.

in the central nervous system (7). In the case of delayed treatment, most child patients will die clinically (8), and there will 
Table V. Univariate analysis for risk factors for NHIE (n).

\begin{tabular}{|c|c|c|c|c|}
\hline & Onset & Normal & $\chi^{2}$ value & P-value \\
\hline \multicolumn{5}{|c|}{ Serum S-100 $\beta$ protein level } \\
\hline Rise & 36 & 4 & \multirow[t]{2}{*}{54.586} & \multirow[t]{2}{*}{$<0.001$} \\
\hline Normal & 2 & 38 & & \\
\hline \multicolumn{5}{|c|}{ Serum CRP level } \\
\hline Rise & 35 & 5 & \multirow[t]{2}{*}{55.000} & \multirow[t]{2}{*}{$<0.001$} \\
\hline Normal & 1 & 39 & & \\
\hline \multicolumn{5}{|c|}{ Serum Cys-C level } \\
\hline Rise & 34 & 6 & \multirow[t]{2}{*}{42.155} & \multirow[t]{2}{*}{0.001} \\
\hline Normal & 4 & 36 & & \\
\hline \multicolumn{5}{|c|}{ Umbilical cord blood TnI level } \\
\hline Rise & 37 & 3 & \multirow[t]{2}{*}{45.255} & \multirow[t]{2}{*}{0.011} \\
\hline Normal & 6 & 34 & & \\
\hline \multicolumn{5}{|c|}{ Umbilical cord blood Mb level } \\
\hline Rise & 36 & 4 & \multirow[t]{2}{*}{54.586} & \multirow[t]{2}{*}{$<0.001$} \\
\hline Normal & 2 & 38 & & \\
\hline \multicolumn{5}{|c|}{ Umbilical cord blood CK-MB level } \\
\hline Rise & 38 & 2 & \multirow[t]{2}{*}{57.836} & \multirow[t]{2}{*}{$<0.001$} \\
\hline Normal & 3 & 37 & & \\
\hline
\end{tabular}

NHIE, neonatal hypoxic ischemic encephalopathy; CRP, C-reactive protein; Cys-C, cystatin C; TnI, troponin I; Mb, myoglobin; CK-MB, creatine kinase-MB.

$$
r=-0.7967, P<0.001
$$

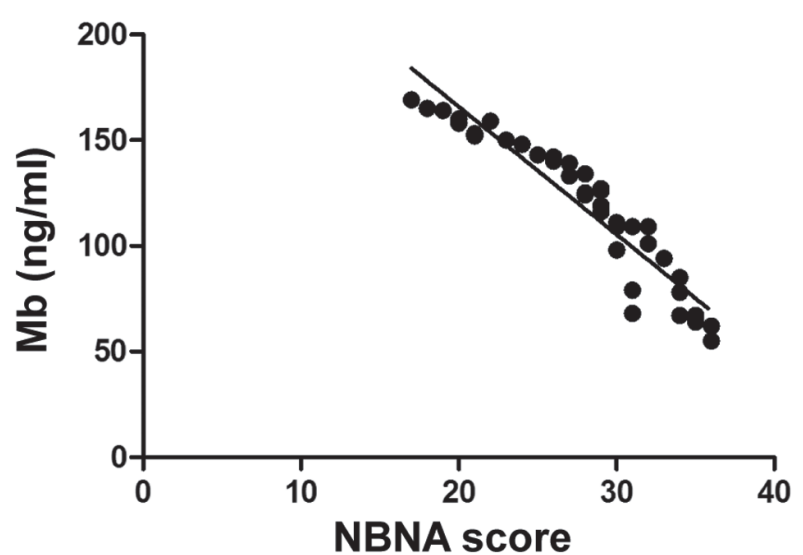

Figure 5. Correlation analysis between NBNA score and umbilical cord blood Mb level. NBNA, neonatal behavioral neurological assessment; Mb, myoglobin.

be different degrees of neurological sequelae even if they survive, seriously affecting the prognosis of patients (9). NHIE is considered as a disease seriously threatening the quality of life and even life health of neonates, as well as one of the most important complications of perinatal asphyxia (10). Studies have proved that the main causes of NHIE are maternal factors (11), such as pregnancy-induced hypertension, anemia during pregnancy, postpartum hemorrhage and placental abnormalities (12) (placenta previa, placental abruption and placental dysfunction), as well as fetal factors (13), such as intrauterine hypoxia and developmental malformation. The $r=-0.9140, P<0.001$

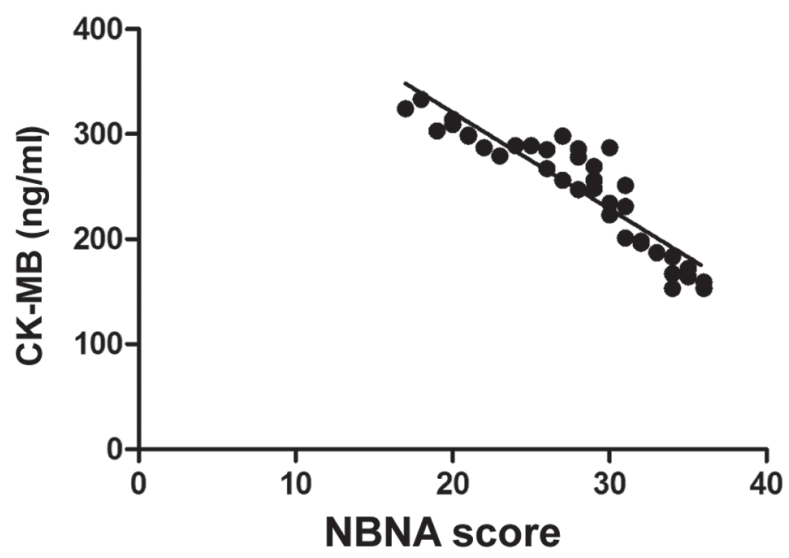

Figure 6. Correlation analysis between NBNA score and umbilical cordblood CK-MB level. NBNA, neonatal behavioral neurological assessment; CK-MB, creatine kinase-MB.

above high-risk factors have been clinically recognized, but not only central nervous system injury but also multiple organ dysfunctions occur in NHIE, especially common in the kidneys, cardiovascular system and respiratory system, which then lead to changes in various inflammatory factors, nerve injury-related factors and myocardial enzymes in vivo. Therefore, the early effective diagnosis and treatment of NHIE is of important significance for reducing the mortality rate and improving the prognosis of child patients (14).

In the present study, the levels of serum S-100 $\beta$, CRP and Cys-C, umbilical cord blood TnI, Mb and CK-MB in NHIE 
Table VI. Multivariate logistic regression analysis for risk factors for NHIE.

\begin{tabular}{lcccccr}
\hline & $\beta$ & SE & W & OR & P-value & $95 \%$ CI \\
\hline Increased level of S-100 $\beta$ & 0.89 & 0.53 & 9.47 & 2.44 & $<0.001$ & $1.38-4.31$ \\
Increased level of CRP & 1.83 & 0.57 & 4.82 & 1.96 & 0.04 & $1.03-7.45$ \\
Increased level of Cys-C & 1.71 & 33.60 & 7.11 & 5.52 & $<0.001$ & $3.10-9.83$ \\
Increased level of TnI & 2.92 & 0.54 & 4.46 & 6.86 & 0.04 & $1.59-9.24$ \\
Increased level of Mb & 1.12 & 5.50 & 6.38 & 3.07 & $<0.001$ & $1.76-5.34$ \\
Increased level of CK-MB & 2.34 & 0.46 & 9.92 & 2.81 & 0.01 & $1.21-4.40$
\end{tabular}

NHIE, neonatal hypoxic ischemic encephalopathy; CRP, C-reactive protein; Cys-C, cystatin C; TnI, troponin I; Mb, myoglobin; CK-MB, creatine kinase-MB.

patients were analyzed. It was found in the comparison of levels of serum S-100 $\beta$ protein, CRP and Cys-C between the two groups that their levels in observation group were significantly higher than those in control group, indicating that the levels of serum S-100 $\beta$ protein, CRP and Cys-C in NHIE patients are significantly higher than those in normal children. The comparison of the levels of umbilical cord blood TnI, Mb and CK-MB between the two groups showed that their levels in observation group were also significantly higher than those in control group, suggesting that the levels of umbilical cord blood TnI, Mb and CK-MB obviously rise in NHIE patients. At the same time, the correlations between NBNA score and changes in serum $\mathrm{S}-100 \beta$ protein, CRP and Cys-C, and umbilical cord blood $\mathrm{TnI}, \mathrm{Mb}$ and $\mathrm{CK}-\mathrm{MB}$ were analyzed, and the results revealed that the NBNA score was negatively correlated with the changes in serum S-100 $\beta$ protein, CRP and $\mathrm{Cys}-\mathrm{C}$ as well as the umbilical cord blood TnI, Mb and CK-MB, further suggesting that with the increasing severity of nervous system dysfunction and disease, the levels of nerve injury-related factors and inflammation are higher and the myocardial damage is more severe in NHIE patients. Finally, the related and independent risk factors for NHIE were analyzed. The results manifested that the levels of serum S-100 $\beta$ protein, CRP and Cys-C, and umbilical cord blood TnI, Mb and CK-MB were related risk factors for NHIE. The increased levels of serum S-100 $\beta$ protein, CRP and Cys-C, and umbilical cord blood TnI, Mb and CK-MB were independent risk factors for NHIE.

In neonatal hypoxia-ischemia, $\mathrm{S}-100 \beta$ protein enters the blood through the blood-brain barrier, increasing the level of serum S-100 $\beta$ protein. In particular, after central nervous system injury definitely occurs in NHIE, the blood-brain barrier is further destroyed, so the level of serum S-100 $\beta$ protein significantly increases (15). At the same time, the level of Cys- $\mathrm{C}$ is also increased, and it has a certain correlation with the local cerebrovascular stimuli in the central nervous system (16), which will aggravate vasospasm (17) and metabolic disorders in the body, induce microcirculation disturbance and platelet aggregation, worsen ischemia and hypoxia in brain tissues, and lead to the increase of CRP level (18). In addition, when asphyxia occurs, there will be obvious hypoxic-ischemic changes in the central nervous system, and the aerobic metabolism is replaced with anaerobic glycolysis to cause massive accumulation of lactic acid, thereby resulting in myocardial injury, competitive inhibition of intracellular calcium iononproteases and excitation-contraction coupling (19), and aggravating the degradation of binding troponin in the cytoplasm. In addition, myocardial injury is further aggravated due to the effect of lipid peroxides, so the levels of umbilical cord blood TnI, Mb and CK-MB all obviously rise (20).

In conclusion, in NHIE patients, the levels of serum S-100 $\beta$ protein, CRP and Cys-C, and umbilical cord blood TnI, Mb and CK-MB all significantly rise, and they have negative correlations with the nervous system function after onset.

\section{Acknowledgements}

Not applicable.

\section{Funding}

No funding was received.

\section{Availability of data and materials}

All data generated or analyzed during this study are included in this published article.

\section{Authors' contributions}

BW and GZ designed the study and performed the experiments, BW and XP established the animal models, GZ and JM collected the data, YL and JL analyzed the data, BW and GZ prepared the manuscript. All authors read and approved the final manuscript.

\section{Ethics approval and consent to participate}

This study was approved by the Ethics Committee of Hospital Attached to the Binzhou Medical University (Binzhou, China). Signed informed consents were obtained from the parents and/ or guardians of the child participants before the study.

\section{Patient consent for publication}

Not available. 


\section{Competing interests}

The authors declare no competing interests.

\section{References}

1. Maggiotto LV, Sondhi M, Shin BC, Garg M and Devaskar SU: Circulating blood cellular glucose transporters - Surrogate biomarkers for neonatal hypoxic-ischemic encephalopathy assessed by novel scoring systems. Mol Genet Metab 127: 166-173, 2019.

2. Chen HM, Gao LX, Wang JJ and Gao C: The correlation between AGT gene polymorphism and neonatal hypoxic-ischemic encephalopathy (HIE). Eur Rev Med Pharmacol Sci 23: 2194-2199, 2019.

3. Davies A, Wassink G,BennetL, Gunn AJ and Davidson JO: Can we further optimize therapeutic hypothermia for hypoxic-ischemic encephalopathy? Neural Regen Res 14: 1678-1683, 2019.

4. Enweronu-Laryea C, Martinello KA, Rose M, Manu S, Tann CJ, Meek J, Ahor-Essel K, Boylan GB and Robertson NJ: Core temperature after birth in babies with neonatal encephalopathy in a sub-Saharan African hospital setting. J Physiol 597: 4013-4024, 2019.

5. Chin EM,Jayakumar S, Ramos E, Gerner G, Soares BP,CristofaloE, Leppert M, Allen M, Parkinson C, Johnston M, et al: Preschool language outcomes following perinatal hypoxic-ischemic encephalopathy in the age of therapeutic hypothermia. Dev Neurosci: Jun 5, 2019 (Epub ahead of print). doi: 10.1159/000499562.

6. Kovacs K, Szakmar E, Meder U, Szakacs L, Cseko A, Vatai B, Szabo AJ, McNamara PJ, Szabo M and Jermendy A: A randomized controlled study of low-dose hydrocortisone versus placebo in dopamine-treated hypotensive neonates undergoing hypothermia treatment for hypoxic-ischemic encephalopathy. J Pediatr 211: 13-19.e3, 2019.

7. Wang M, Liu C, Li X, Liu H, Jin C, Tao X, Wang X, Zhao H, Cheng Y, Wu F, et al: Isolated periventricular pseudocysts do not affect white matter microstructure development in neonatal stage: A retrospective case-control diffusion tensor imaging study. Eur J Radiol 116: 152-159, 2019.

8. Yang XL, Wang X, Shao L, Jiang GT, Min JW, Mei XY, He XH, Liu WH, Huang WX and Peng BW: TRPV1 mediates astrocyte activation and interleukin-1 $\beta$ release induced by hypoxic ischemia (HI). J Neuroinflammation 16: 114, 2019.

9. Kim YE, Sung SI, Chang YS, Ahn SY, Sung DK and Park WS: Thrombin preconditioning enhances therapeutic efficacy of human Wharton's Jelly-derived mesenchymal stem cells in severe neonatal hypoxic ischemic encephalopathy. Int J Mol Sci 20: 2477, 2019.
10. Jiang F, Yang M, Wu C and Wang J: Potential roles of miR-374a-5p in mediating neuroprotective effects and related molecular mechanism. J Mol Neurosci 69: 123-132, 2019.

11. Scheidegger S, Held U, Grass B, Latal B, Hagmann C and Brotschi B; National Asphyxia and Cooling Register Group: Association of perinatal risk factors with neurological outcome in neonates with hypoxic ischemic encephalopathy. J Matern Fetal Neonatal Med: Jun 4, 2019 (Epub ahead of print). doi: 10.1080/14 767058.2019.1623196.

12. SakhujaP,More K, Ting JY,ShethJ,Lapointe A,Jain A,McNamaraPJ and Moore AM: Gastrointestinal hemodynamic changes during therapeutic hypothermia and after rewarming in neonatal hypoxic-ischemic encephalopathy. Pediatr Neonatol: Apr 16, 2019 (Epub ahead of print). doi: 10.1016/j.pedneo.2019.04.003.

13. Cánovas-Ahedo $\mathrm{M}$ and Alonso-Alconada D: Combined therapy in neonatal hypoxic-ischaemic encephalopathy. An Pediatr (Barc) 91: 59.e1-59.e7, 2019 (In Spanish).

14. O'Brien CE, Santos PT, Kulikowicz E, Reyes M, Koehler RC, Martin LJ and Lee JK: Hypoxia-ischemia and hypothermia independently and interactively affect neuronal pathology in neonatal piglets with short-term recovery. Dev Neurosci 41: 17-33, 2019.

15. Tani N, Ikeda T, Shida A, Aoki Y, Oritani S and Ishikawa T: Postmortem water contents of major organs with regard to the cause of death. J Forensic Leg Med 65: 48-54, 2019.

16. Chu X, Cao L, Yu Z, Xin D, Li T, Ma W, Zhou X, Chen W, Liu D and Wang Z: Hydrogen-rich saline promotes microglia M2 polarization and complement-mediated synapse loss to restore behavioral deficits following hypoxia-ischemic in neonatal mice via AMPK activation. J Neuroinflammation 16: 104, 2019.

17. Liu Y, Wang H,Liu N, Du J,Lan X, Qi X,Zhuang C, Sun T,Li Y and Yu J: Oxymatrine protects neonatal rat against hypoxic-ischemic brain damage via PI3K/Akt/GSK3 $\beta$ pathway. Life Sci: May 15, 2019 (Epub ahead of print). doi: 10.1016/j.lfs.2019.04.070.

18. Zou L, Yuan H,Liu Q,Lu Cand Wang L: Potential protective effects of bilirubin following the treatment of neonatal hypoxic-ischemic encephalopathy with hypothermia therapy. Biosci Rep: Jun 4, 2019 (Epub ahead of print). doi: 10.1042/BSR20182332.

19. Ciobanou A, Jabak S, De Castro H, Frei L, Akolekar R and Nicolaides KH: Biomarkers of impaired placentation at 35-37 weeks' gestation in the prediction of adverse perinatal outcome. Ultrasound Obstet Gynecol 54: 79-86, 2019.

20. Arriagada S, Huang H, Fletcher K and Giannone P: Prevention of excessive hypothermia in infants with hypoxic ischemic encephalopathy prior to admission to a quaternary care center: A neonatal outreach educational project. J Perinatol 39: 1417-1427, 2019.

(i) $($ ) This work is licensed under a Creative Commons Attribution-NonCommercial-NoDerivatives 4.0 International (CC BY-NC-ND 4.0) License. 